\title{
Novel approaches to the diagnosis of pancreatic disease in childhood
}

\author{
RICHARD TL COUPER MBChB FRACP
}

\begin{abstract}
RTL COUPER. Novel approaches to the diagnosis of pancreatic disease in childhood. Can J Gastroenterol 1997;11(2):153. 156. The diagnosis of pancreatic disease is difficult. Most tests of pancreatic function need to be interpreted in the context of the patient's presenting history and clinical examination. In childhood, classical signs of hemorrhagic pancreatitis are seldom useful because they rarely occur. A careful history is particularly useful in conditions with an autosomal dominant inheritance such as hereditary pancreatitis. Pedigree construction should be undertaken in all cases of pancreatitis. Assessment of exocrine pancreatic function is made easier by a thorough appreciation of the constellation of signs, both pancreatic and extrapancreatic, of various pancreatic disease. The purpose of this review is to explore novel means of diagnosing pancreatic disease, including pancreatic function testing, organ imaging and, more recently, molecular biology techniques. Most of the potentially novel techniques surround organ imaging or molecular biology.
\end{abstract}

Key Words: Childhood, Diagnosis, Pancreatic disease

\section{Nouvelles approches pour le diagnostic de la maladie pancréatique chez l'enfant}

RÉSUMÉ : Le diagnostic de la maladie pancréatique est difficile à poser Les tests plus récents de fonction pancréatique doivent être interprétés dans le contexte du tableau et de l'examen cliniques. Dans l'ensemble, les signes classiques de pancréatite hémorragique sont rarement utiles parce que peu fréquents. Une anamnèse attentive est particulièrement utile en présence de maladie héréditaire autosomique dominante, comme c'est le cas de la pancréatite héréditaire. Dans tous les cas de pancréatite, il faut bâtir la généalogie. L'évaluation de la fonction pancréatique exocrine est facilitée par un examen approfondi de la constellation des signes tant pancréatiques qu'extra-pancréatiques propres à diverses maladies du pancréas. Le but de cette synthèse est d'explorer de nouveaux moyens de diagnostiquer la maladie pancréatique, y compris les épreuves de fonction pancréatique, l'imagerie et, plus récemment, les techniques de biologie moléculaire. La plupart de ces nouvelles techniques concernent l'imagerie et la biologie moléculaire.
$\mathrm{T}$ he diagnosis of pancreatic disease is difficult. Not only are the etiopathogenetic mechanisms responsible for most pancreatic diseases unknown, but also the pancreas and its secretions are inaccessible. Most tests of pancreatic function need to be interpreted in the context of the patient's presenting history and clinical examination. For example, severe constant abdominal pain radiating thorough to the back is very suggestive of acute pancreatitis. Attempts to alleviate pain by propping up on all fours (Ingelfinger's sign) is almost pathognomic of acute pancreatitis. Marked elevation of serum amylase is not diagnostic of acute pancreatitis but in the clinical situation described is a useful diagnostic adjunct. In childhood, classical signs of hemorrhagic pancreatitis, such as Cullen and Grey Turner signs, umbilical discolouration and discolouration of the flanks, are seldom useful because they rarely occur.

A careful history is particularly useful in conditions with an autosomal dominant inheritance such as hereditary pancreatitis. Pedigree construction should be undertaken in all cases of pancreatitis. A history of recurrent infections in a patient with short stature and pancreatic insufficiency may suggest Shwachman syndrome (exocrine pancreatic dysfunc-

This paper was part of a symposium entitled 'Selected topics in pediatric gastroenterology and nutrition' held in October 1995 to honour the academic career of Dr Gordon G Forstner

University Department of Paediatrics, University of Adelaide, and Department of Gastroenterology, Women's and Children's Hospital, North Adelaide, South Australia

Correspondence: Dr RTL Couper, University Department of Paediatrics, University of Adelaide, Women's and Children's Hospital, King William Road, North Adelaide, South Australia, 5006. Telephone 011-61-8-204-7266, fax 011-61-8-204-7031, e-mail rcouper@medicine.adelaide.edu.au 


\section{TABLE 1 \\ Imaging modalities}

Plain abdominal x-ray
Ultrasonography
Endoscopic ultrasound
Computed tomography scan: conventional
Computed tomography scan: helicospiral
Magnetic resonance imaging cholangiography
Positron emission tomography scan
Somatostatin receptor imaging
Radioimmunolocalization
Digital subtraction angiography
Endoscopic retrograde cholangiopancreatography

tion, neutropenia and metaphyseal dysplasia) (1). A history of metabolic muscle disorders or early infant death may suggest Pearson bone marrow pancreas syndrome (a mitochondrial DNA disorder characterized by exocrine pancreatic dysfunction and sideroblastic anemia) $(2,3)$.

Thus, assessment of exocrine pancreatic function is made easier by a thorough appreciation of the constellation of signs, both pancreatic and extrapancreatic, for various pancreatic disease. The following examples illustrate this point. in Shwachman syndrome quantification of pancreatic function is often difficult and requires invasive and expensive direct pancreatic function testing. Demonstration of a fatty pancreas on ultrasound $(4,5)$ (bright echoes) or a radiolucent pancreas on computed tomography $(\mathrm{CT})$ scan $(4,5)$, characteristic hematological abnormalities, disordered neutrophil chemotaxis (6) and metaphysical dysplasia help to seal the diagnosis. Clinical characterization of other pancreatic disorders, such as Johanson-Blizzard syndrome (exocrine pancreatic dysfunction, hypoplastic alae nasi and sensorineural deafness) (7) and Pearson bone marrow pancreas syndrome, may obviate the need for invasive tests. Patients with Johanson-Blizzard syndrome have a characteristic facial appearance with hypoplastic alae nasi, and approximately $75 \%$ have sensorineural deafness due to the Mondini malformation which can be detected by CT scans of the petrous temporal bone (8). Pearson bone marrow pancreas syndrome is characterized by sideroblastic anemia and variable suppression of other hematopoietic elements. Ring sideroblasts on bone marrow aspiration strongly suggest this diagnosis (2).

The purpose of this review is to explore novel means of diagnosing pancreatic disease, which include pancreatic function testing, organ imaging and, more recently, molecular biology techniques. Most of the potentially novel techniques involve organ imaging or molecular biology.

\section{PANCREATIC FUNCTION TESTING}

There are three categories of exocrine pancreatic function tests (Table 1): direct tests, which analyze the output of fluid, electrolytes and enzymes from the stimulated pancreas; indirect tests, which detect the consequences of pancreatic maldigestion of normal food substrates or synthetic substrates; and blood tests, which measure circulating pancre- atic enzymes or hormones. Considerable ingenuity has resulted in these tests but the ideal pancreatic function pancreatic test remains the 'holy grail' of pancreatology.

Only direct tests delineate pancreatic function in patients with impaired pancreatic function but sufficient pancreatic enzyme output to maintain normal digestion. The only conditions in which these tests are diagnostic are isolate enzyme deficiencies, including congenital trypsinogen deficiency, congenital pancreatic lipase deficiency and colipase deficiency (9-11). Disproportionate reduction of fluid and bicarbonate and chloride ion output in biliopancreatic secretions is highly suggestive of cystic fibrosis $(12,13)$, but direct tests are hardly the method of choice for diagnosis. The secretin cholecystokinin pancreatic stimulation test may be useful in the occasional patient with unknown genotype and an equivocal sweat chloride. However, this test is not widely available and often impractical. It is also invasive, complex and time-consuming; due to a lack of standardization each centre needs to validate the test in their patient population to obtain a normal range.

There is a profusion of indirect pancreatic tests. These tests will usually detect only patients with steatorrhea, and most tests are no more useful than the original indirect pancreatic function test, the three- to five-day fecal fat collection. Many indirect tests are not specific for pancreatic disease and will detect malabsorption or malassimilation of nutrients secondary to intestinal or biliary tract disease. Tests that rely on pancreatic specific enzymes, such as cholesterol esterase, ie, the fluorescein dilaurate test (14) and the ${ }^{13} \mathrm{C}$ cholesteryl octanoate (15) test, partially overcome this deficiency. None of these tests nor the blood tests allow the appending of a specific diagnosis.

\section{ORGAN IMAGING}

There have been considerable advances in imaging of the exocrine pancreas. Organ imaging modes are outlined in Table 1. Only newer modalities are discussed below.

Endoscopic ultrasound may have an improved ability to detect small pancreatic lesions compared with conventional ultrasonography. This ability is principally useful for tumour diagnosis, a rare problem in childhood. This modality can be useful for identifying tumours such as gastrinoma, but is probably no more useful that $\mathrm{CT}$ scan or magnetic resonance imaging (MRI) (16). It has some value, however, to visualize the common bile duct and possible pancreatic ducts when endoscopic retrograde cholangiopancreatography (ERCP) is impractical (17). Although of limited applicability, endoscopic evidence of duct dilation following intravenous secretin has been suggested as a diagnostic test for chronic pancreatitis (18). Very few pediatric gastroenterology units have access to an endoscopic ultrasound.

CT is a useful modality for assessing pancreatic disease. The following disorders may have characteristic or suggestive findings on CT: annular pancreas, cystic fibrosis, Shwachman syndrome, hereditary pancreatitis, Von Hippel Lindau syndrome, pancreatic pseudocyst, pancreaticoblastoma, insulinoma and VIPoma (19). However, most of these disor- 
ders will also have characteristic appearances on conventional ultrasound and MRI scan. It is not a particularly useful modality for assessing pancreatic fibrosis. Helicospiral CT scanning, which consists of continuous image acquisition, can speed up scan time and allows construction of three-dimensional images (20). Lesional enhancement techniques and selective attenuation of surrounding tissues make this a particularly useful technique with which to look at tumours and blood vessels. If available, this technique is superior to conventional CT scan.

MRI is now considered a very good technique for imaging the pancreas. Early MRI scans had considerable problems with abdominal imaging because of the effects of movement on the signal:noise ratios. This resulted in inadequate delineation of the bowel, especially if fluid were present (21). Movement artefact can be reduced or eliminated by a variety of techniques, including breath-holding, fast low angle shot, fat suppressed spin-echo and echoplanar imaging $(22,23)$. Intravenous gadopentetate dimeglumine may be used to enhance lesions (22). A variety of agents, including carbon dioxide, ferrous ammonium citrate, paramagnetic iron oxide and kaopectate, have been used as bowel contrast. These agents will be supplanted by oral gadolinium preparations. Excellent images are now obtained with both $T_{1}$ and $T_{2}$ weighted images. $T_{2}$ images can be used to generate MRI cholangiograms (24) and may visualize pancreatic ducts. This technique may be useful if ERCP is difficult. It will not, however, differentiate between obstruction and a tight stenosis.

Position emission tomography (PET), which is used primary as an investigational tool for amino acid handicaps $(25,26)$, has also been used infrequently as a pancreatic imaging modality. The exocrine pancreas has a high propensity for amino acid uptake. Labelling amino acids with an unstable position emitting isotope $\left({ }^{11} \mathrm{C}\right.$ or $\left.{ }^{13} \mathrm{~N}\right)$ allows a dynamic assessment of pancreatic function. This imaging modality may be useful for tumour assessment, particularly small hormone secreting tumours. Specificity may be improved by assessing uptake of ${ }^{18} \mathrm{~F}$-deoxyglucose (27). However, it is extremely expensive, and very few pediatric centres have access to a PET scanner.

Somatostatin receptor imaging relies on a number of hormone secreting tumours that have an increased expression of somatostatin receptors. Following intravenous administration, a somatostatin analogue labelled with either ${ }^{123}$ I or ${ }^{111}$ In can be detected using single photon emission computerized tomography. Other hormones may be similarly labelled. This method has proven useful for imaging gastrinomas in adults $(28,29)$.

Radioimmunolocalization involves labelling antibodies to cell surface markers (30). Although most markers are not particularly specific to the pancreas, this technique has been used experimentally for tumour detection.

Digital subtraction has improved angiography by reducing the amount of contrast required and improving venous phase images. Angiography, however, is invasive and seldom needed in children. MRI and helicospiral CT scanning fre- quently provide adequate vascular images for diagnostic purposes.

ERCP remains the method of choice for visualizing the pancreaticobiliary tree. ERCP can be successfully performed in small infants (31). Most pediatric units use the services of a skilled adult gastroenterologist. Endoscopic ultrasound and MRI cholangiography may be useful when ERCP is impractical.

\section{MOLECULAR DIAGNOSIS}

The diagnosis of pancreatic disease using molecular methods is an emerging science. Currently only cystic fibrosis and Pearson bone marrow pancreas syndrome can be confidently diagnosed by molecular techniques. There are more than 600 known mutations of the cystic fibrosis gene (32). Most clinical laboratories only screen for five to seven of the most common mutations which, depending upon the ethnic background of the population, will establish the diagnosis in approximately $50 \%$ to $80 \%$ of patients. If further screening is required, material is sent to a reference laboratory. Pearson bone marrow pancreas syndrome, which is due to a large mitochondrial deletion (33), may be amenable to molecular diagnosis. The mitochondrial genome is completely defined and should be detectable in virtually all patients by careful use of mitochondrial probes. However, patients may display heteroplasty; consequently the deletion may be present in some tissues and absent in others. Evaluation of two tissues, eg, white cells and fibroblasts or liver tissue, may help to circumvent this problem. Occasionally mitochondrial disease may be due to a defect in mitochondrial proteins expressed in genomic DNA; in these circumstances diagnosis may not be possible (33).

The genes for colipase, trypsinogen and lipase have been provisionally assigned to $6 \mathrm{p} 21.1$-pter, $7 \mathrm{q} 22$-qter and $10 \mathrm{q}$ 24-q26, respectively (34-36). The precise gene location and sequence have not been elucidated. cDNAs for each of the proteins have been identified. Indeed, the cDNA for human lipase has been inserted into a transformed human gallbladder epithelial line in vitro (37). However, in the absence of precise gene location and mutation-specific probes, current mutation detection techniques do not allow disease diagnosis. However, if the protein's amino acid sequence is known, it should be possible to design a series of overlapping primers and use polymerase chain reaction amplification and direct sequencing to identify mutations in these rare disorders.

The gene and gene product have not been identified in Shwachman syndrome, Johanson-Blizzard syndrome and hereditary pancreatitis. In conditions such as Shwachman syndrome, which displays diverse pathology involving a large number of tissues, evidence of chromosome microdeletion can be sought using fluorescent in situ hybridization. Azzara et al (38) suggested that a cytoskeletal protein defect is responsible for the neutrophil chemotaxis defect in Shwachman syndrome. If the gene product can be identified, it may be possible to identify a cDNA and localize the chromosomal disorder. Alternatively, searching a gene database may allow these steps to be bypassed. 


\section{SUMMARY}

Spectacular technical advances in organ imaging have allowed improved visualization of the pancreas. These techniques may have a limited applicability in pediatric pancreatic disease. Molecular biology has considerable potential in pancreatic disease but only cystic fibrosis and Pearson bone marrow pancreas syndrome can be diagnosed by these means. None of the advances in pancreatic diagnosis can substitute for clinical acumen.

\section{REFERENCES}

1. Aggett PJ, Cavanagh NPC, Mathew DJ, Pincott JR, Sutcliffe J, Harries JT. Shwachman's syndrome. Arch Dis Child 1980;55:331-47.

2. Pearson HA, Lobel JS, Kocoshis SA, et al. A new syndrome of refractory anaemia with vacuolization of marrow precursors and exocrine pancreatic dysfunction. J Pediatr 1979;95:976-84.

3. Bernes SM, Bacino C, Prezant TR, et al. Identical mitochondrial deletion in mother with progressive external opthalmoplegia and son with Pearson marrow-pancreas syndrome. J Pediatr 1993;123:598-602.

4. Robberecht E, Nachtegaele P, Van-Rattinghe R, Afschrift M, Kunnen M, Verhaaren R. Pancreatic lipomatosis in the Shwachman-Diamond syndrome. Identification by sonography and CT scan. Pediatr Radiol 1985;15:348-9.

5. Wilschanski M, van der Hoeven E, Phillips J, Shuckett B, Durie P. Shwachman-Diamond syndrome presenting as hepatosplenomegaly. J Pediatr Gastroenterol Nutr 1994;19:111.

6. Thong YH. Impaired neutrophil kinesis in a patient with the Shwachman-Diamond syndrome. Aust Paediatr J 1978;14:34-7.

7. Johanson A, Blizzard R. A syndrome of congenital aplasia of the alae nasi/deafness, lipothyroidism, dwarfism, absent permanent teeth and malabsorption. J Pediatr 1975;87:241-3.

8. Braun J, Lerner A, Gershoni-Baruch R. The temporal bone in the Johanson-Blizzard syndrome: A CT study. Pediatr Radiol 1991;21:580-3.

9. Townes PL, Bryson MF, Miller G. Further observations of trypsinogen deficiency disease: report of a second case. J Pediatr 1967;71:220-4.

10. Sheldon W. Congenital pancreatic lipase deficiency. Arch Dis Child 1964;39:268-71.

11. Hildebrand H, Bergstrom B, Bekassy A, Erianson-Albertson C, Helin I. Isolated colipase deficiency in two brothers. Gut 1982;23:243-6.

12. Kopelman H, Durie P, Gaskin K, Weizman Z, Forstner G. Pancreatic fluid secretion and protein hyperconcentration in cystic fibrosis. N Engl J Med 1985;313:329-34.

13. Kopelman H, Corey M, Gaskin K, Durie P, Weizman Z, Forstner G. Impaired chloride secretion as well as bicarbonate secretion, underlies the fluid secretory defect in the cystic fibrosis pancreas. Gastroenterology 1988;95:349-55.

14. Cumming JGR, Forsyth JS, Boyd EJS, Frost GJ, Cuschieri A. Diagnosis of exocrine insufficiency in cystic fibrosis by use of fluorescein dilaurate test. Arch Dis Child 1986;61:573-5.

15. Cole SG, Rossi S, Stern A, Hofmann AF. Cholesteryl octanoate breath test preliminary studies on a new noninvasive test of human pancreatic exocrine function. Gastroenterology 1987;93:1372-80.

16. Zuccaro G Jr, Sivak MV Jr. Endoscopic ultrasonography in the diagnosis of chronic pancreatitis. Endoscopy 1992;24(Suppl 1):237-349.
17. Aniouyal P, Amouyal G, Levy P, et al. Diagnosis of choledocholithiasis by endoscopic ultrasonography. Gastroenterology 1994;106:1062-7.

18. Glaser J, Mann O, Pausch J. Diagnosis of chronic pancreatitis by means of a sonographic secretin test. Int J Pancreatol 1994;15:195-200.

19. Herman TE, Siegel MJ. CT of the pancreas in children. Am J Roentgenol 1991;157:375-9.

20. Fishman EK, Wyatt SH, Ney DR, Kuhlman JE, Siegelman SS. Spiral $\mathrm{CT}$ of the pancreas with multiplanar display. Am J Roentgenol 1992;159:1209-15.

21. Wall SD, Brasch RC, Wootton SL, Goldberg HI. Improved imaging of the GI tract and pancreas. MRI decisions. 1988;2:27-32.

22. Semelka RC, Kroeker MA, Shoenut JP, Kroeker R, Yaffe CS, Micflickier AB. Pancreatic disease: Prospective comparison of CT, ERCP and 1.5-T MR imaging with dynamic gadolinium enhancement and fat suppression. Radiology 1991;181:785-90.

23. Reimer P, Saini S, Hahn PF, Mueller PR, Brady TJ, Cohen MS Techniques for high-resolution echo-planar MR imaging of the pancreas. Radiology 1992;182:175-9.

24. Guibaud L, Bret PM, Reinhold C, Atri M, Barkun ANG. Diagnosis of choledocholithiasis: Value of MR cholangiography. Am J Roentgenol 1994;163:847-50.

25. Syrota A, Dop-Ngassa M, Cerf M, Paraf A. ${ }^{14} \mathrm{C}$-L-methionine for evaluation of pancreatic exocrine function. Gut 1981;22:907-15.

26. Kubota K, Fukuda H, Yamada K, et al. Experimental pancreas imaging study with ${ }^{13} \mathrm{~N}$ glutamate using positron computer tomography. Eur J Nucl Med 1983;8:528-30.

27. Klever P, Bares R, Fass J, Bull TJ, Schumpelick V. PET with fluorine18 deoxyglucose for pancreatic disease. Lancet 1992;340:1158-9.

28. Lamberts SWJ, Holland LJ, van Koetsveld PM, et al. Parallel in vivo and in vitro detection of functional somatostatin receptors in human endocrine pancreatic tumors: Consequences with regard to diagnosis, localization and therapy. J Clin Endocrinol Metab 1990;71:566-74.

29. Tan CK, Podila PV, Taylor JE, et al. Human cholangiocarcinomas express somatostatin receptors and respond to somatostatin with growth inhibition. Gastroenterology 1995;108:1908-16.

30. Allum WH. Radioimmunolocalization of tumours of the pancreas and biliary tree. Baillieres Clin Gastroenterol 1990;4:853-67.

31. Guelrud M, Jaen D, Torres P, et al. Endoscopic retrograde cholangiopancreatography in the infant: Evaluation of a new prototype pediatric duodenoscope. Gastrointest Endosc 1977;24:33-4.

32. Harris A. Cystic fibrosis. Q J Med 1995;88:229-32.

33. De Vivo DC. The expanding clinical spectrum of mitochondrial disease. Brain Dev 1993;15:1-22.

34. Davis RC, Xia Y, Mohandas T, Schotz MC, Lusis AJ. Assignment of the human pancreatic colipase gene to chromosome $6 \mathrm{p} 21.1$ to pter. Genomics 1991;10:262-5.

35. Honey NK, Sakaguchi AY, Quinto C, et al. Chromosomal assignments of human genes for serine proteases trypsin, chymotrypsin B and elastase. Somat Cell Mol Genet 1984;10:369-76.

36. Davis RC, Diep A, Hunziker W, et al. Assignment of human pancreatic lipase gene (PNLIP) to chromosome 10 q24-q26. Genomics 1991;11:1164-6.

37. Maeda H, Danel C, Crystal RG. Adenovirus-mediated transfer of human lipase complementary cDNA to the gallbladder. Gastroenterology 1994;106:1638-44.

38. Azzara A, Carulli G, Ceccarelli M, Pucci C, Raggio R, Ambrogi F. In vivo effectiveness of lithium on impaired neutrophil chemotaxis in Shwachman Diamond syndrome. Acta Haematol 1991;85:102. 


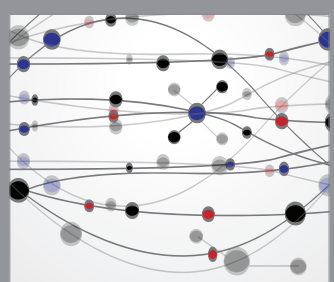

The Scientific World Journal
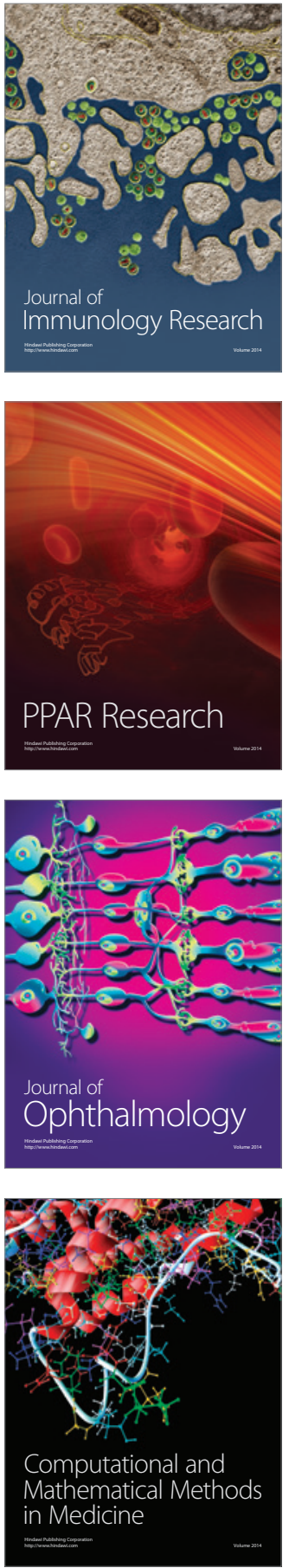

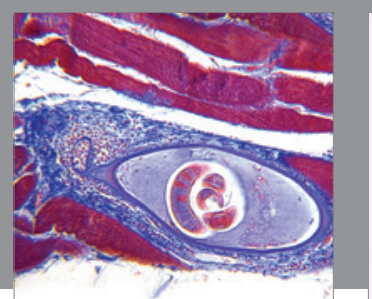

Gastroenterology Research and Practice

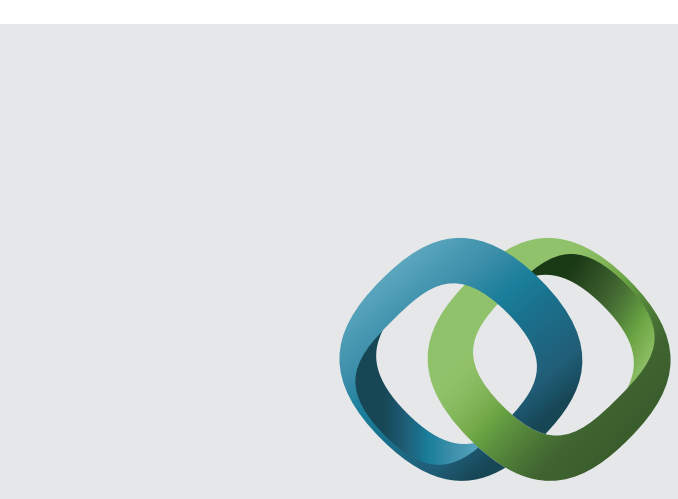

\section{Hindawi}

Submit your manuscripts at

http://www.hindawi.com
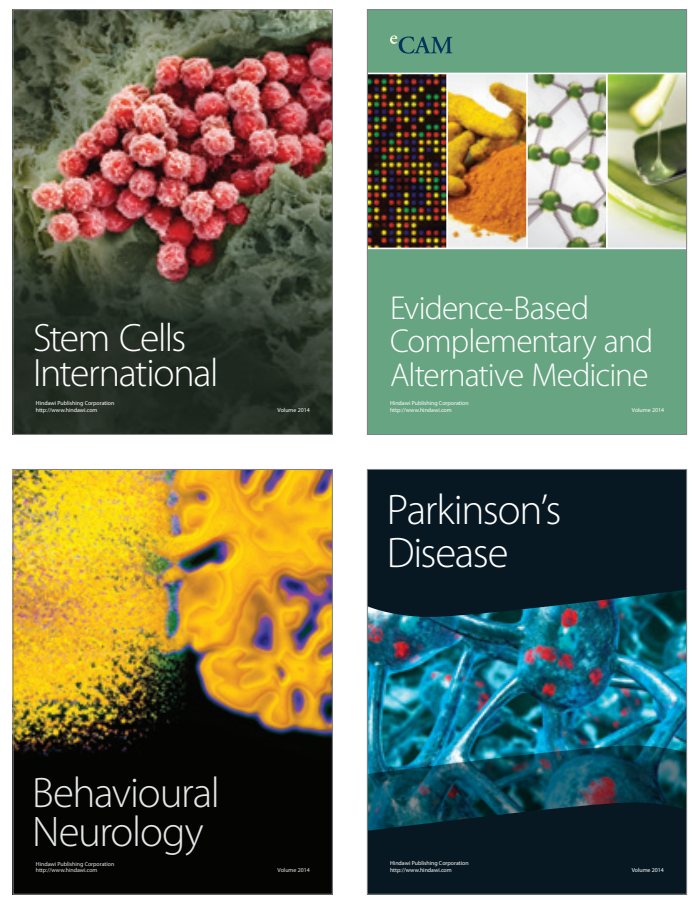
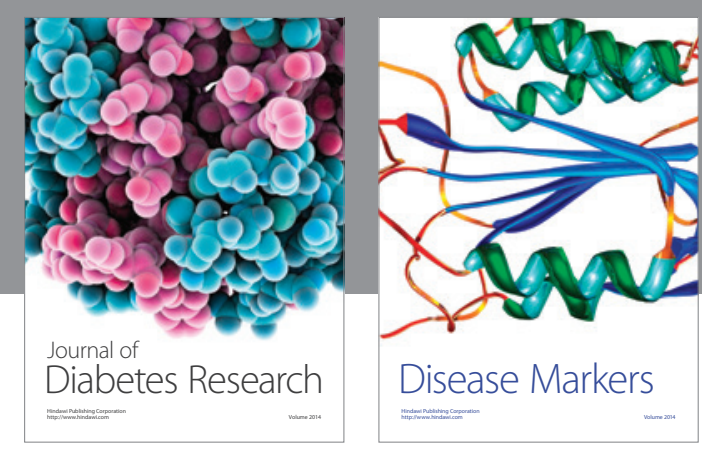

Disease Markers
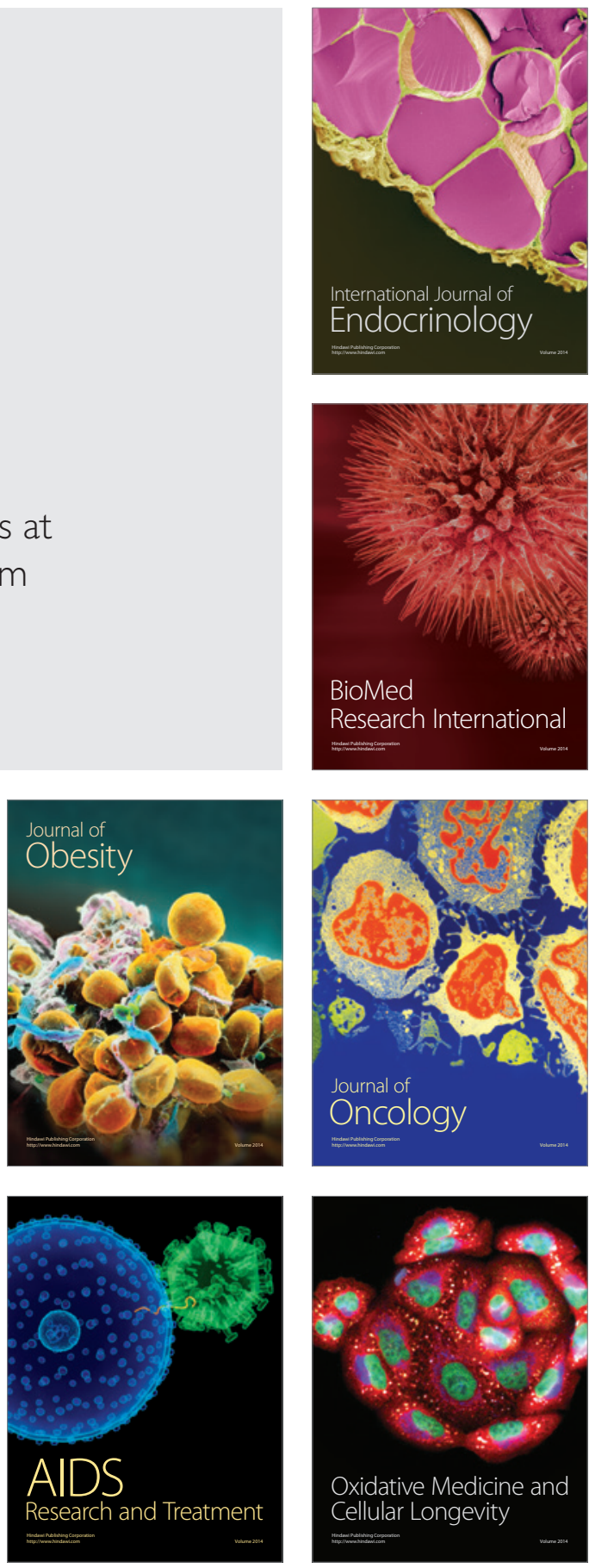